\title{
GA-A24486
}

\section{PRACTICAL EXPERIENCES \\ WITH THE 6 GYROTRON SYSTEM \\ ON THE DIII-D TOKAMAK}

\author{
by \\ J. LOHR, W.P. CARY, Y.A.GORELOV, H.J. GRUNLOH, \\ K. KAJIWARA, J.J. PEAVY, D. PONCE, J. TOOKER, \\ and R.W. CALLIS
}

MARCH 2004 


\section{DISCLAIMER}

This report was prepared as an account of work sponsored by an agency of the United States Government. Neither the United States Government nor any agency thereof, nor any of their employees, makes any warranty, express or implied, or assumes any legal liability or responsibility for the accuracy, completeness, or usefulness of any information, apparatus, product, or process disclosed, or represents that its use would not infringe privately owned rights. Reference herein to any specific commercial product, process, or service by trade name, trademark, manufacturer, or otherwise, does not necessarily constitute or imply its endorsement, recommendation, or favoring by the United States Government or any agency thereof. The views and opinions of authors expressed herein do not necessarily state or reflect those of the United States Government or any agency thereof. 
GA-A24486

\title{
PRACTICAL EXPERIENCES WITH THE 6 GYROTRON SYSTEM ON THE DIII-D TOKAMAK
}

\author{
by \\ J. LOHR, W.P. CARY, Y.A.GORELOV, H.J. GRUNLOH, \\ K. KAJIWARA, J.J. PEAVY, D. PONCE, J. TOOKER, \\ and R.W. CALLIS
}

This is a preprint of a paper presented at the 20th IEEE/NPSS Symposium on Fusion Engineering, San Diego, California, October 14-17, 2003 and to be published in Fusion Science and Technology.

\author{
Work supported by \\ the U.S. Department of Energy \\ under Contract No. DE-AC03-99ER54463
}

GENERAL ATOMICS PROJECT 30033

MARCH 2004 


\title{
Practical Experiences with the 6 Gyrotron System on the DIII-D Tokamak
}

\author{
John Lohr, W.P. Cary, Y.A. Gorelov, H.J. Grunloh, K. Kajiwara, J.J. Peavy, D. Ponce, \\ J. Tooker, and R.W. Callis
}

General Atomics, P.O. Box 85608, San Diego, California $92186-5608$

\begin{abstract}
The gyrotron installation on the DIII-D tokamak now comprises six $110 \mathrm{GHz}$ gyrotrons in the $1 \mathrm{MW}$ class, three manufactured by CPI[1] and three by Gycom [2]. Two tetrode rectifier/modulator/regulator power supplies were constructed to provide power for the CPI gyrotrons. A second system uses three $\mathrm{mod} / \mathrm{reg}$ tetrodes connected in parallel, which are fed by a dual parallel tetrode $\mathrm{mod} / \mathrm{reg}$ to power the Gycom tubes. The windowless evacuated transmission lines are up to $100 \mathrm{~m}$ in length, with $80 \%$ transmission efficiency. Engineering solutions were developed in specific problematic areas encountered in the development of this complex system, including: Gyrotron instability; high voltage circuit instability; gyrotron conditioning; rf beam forming and coupling to waveguide; output window vacuum seals; material control; launcher mechanics and diagnosis; polarizer mechanics; dummy loads; power measurements; polarization measurements; cooling; calorimetry; and operating controls. The system is in routine operation in support of tokamak experiments, with peak generated power of about $5 \mathrm{MW}$ at $2 \mathrm{~s}$. pulse length and about $3 \mathrm{MW}$ for $5 \mathrm{~s}$. pulses. This presentation focuses on practical lessons learned in the development and operation of these systems.
\end{abstract}

\section{INTRODUCTION}

The present $110 \mathrm{GHz}$ gyrotron installation on the DIII-D tokamak [3] has been under development for about seven years, beginning with a single Gycom gyrotron capable of generating about $0.85 \mathrm{~kW}$ for up to $2.0 \mathrm{~s}$. The system now comprises six gyrotrons in the $1 \mathrm{MW}$ class, three of which have demonstrated $1.0 \mathrm{MW}$ rf output for $5.0 \mathrm{~s}$ pulse length and three generating approximately $0.75 \mathrm{MW}$ for $2.0 \mathrm{~s}$ pulses. The rf power exits the gyrotrons through a vacuum isolation window and is transported to the tokamak at $80 \%$ efficiency in evacuated circular corrugated waveguide up to $100 \mathrm{~m}$ in length. The waveguide system incorporates polarizers, waveguide switches, vacuum isolation valves, integral vacuum pumping, arc detection and fully articulating launchers capable of scanning poloidally over the tokamak upper half plane at tangential injection angles of $\pm 20^{\circ}$ to drive toroidal current in both directions on arbitrary flux surfaces. The system has supported experiments on a wide variety of topical areas including heating and current drive, instability suppression, energy transport and confinement. Although the operation of the system has become rather reliable, there have been some lessons learned, some hardware failures and other problems which have occurred during the development of the installation. These areas are the subject of this paper.

\section{GYROTRONS}

\section{A. Conditioning}

Two general types of gyrotron are in use at DIII-D. There are three Gycom Centaur series tubes having boron nitride output windows, which generate about $750 \mathrm{~kW}$ for $2.0 \mathrm{~s}$ pulses. The oldest of these has been in service for six years and has accumulated over 3,000 filament hours. Gycom supplies tubes fully conditioned to maximum performance, and only about $100 \mathrm{~h}$ of additional local conditioning have been required to achieve $2.0 \mathrm{~s}$ pulses at high output power. The tubes employ getter pumping at three locations in addition to a small vacion pump. The CPI tubes are in the VGT-8110 series and are supplied after a test program at the factory culminating in $10 \mathrm{~s}$ operation at $500-600 \mathrm{~kW}$ and $1.0 \mathrm{MW}$ operation for short pulses. These tubes have required about $2000 \mathrm{~h}$ of total conditioning operation to achieve the acceptance parameters of $1.0 \mathrm{MW}, 5.0 \mathrm{~s}$, of which about $500 \mathrm{~h}$ has been required at the DIII-D site to increase the power to 1.0 MW.

The development of optically transparent gyrotron windows has revealed active light production inside the gyrotrons. The source of the light has not been identified, but the emission is inversely correlated with rf output. That is, unstable gyrotron performance and operation during conditioning tends to result in higher light production.

\section{B. Windows}

Continuous gyrotron operation at $1 \mathrm{MW}$ output power has been made possible by the development of technology for manufacturing disks of artificially grown diamond up to $120 \mathrm{~mm}$ in diameter and about $2 \mathrm{~mm}$ thick. When used as a gyrotron output window, these disks absorb only about $0.2 \%$ of the transmitted rf power. Coupled with thermal conductivity of $2 \mathrm{~kW} / \mathrm{m}-\mathrm{K}$, about five times that of copper, the windows can be cooled at the periphery by water and the central temperature remains less than about $150^{\circ} \mathrm{C}$ for a Gaussian $1.0 \mathrm{MW}$ beam. The excellent properties of this material make it difficult to determine the rf output power using calorimetric measurements of the window cooling water and also make it difficult to determine the window temperature using infrared techniques owing to the very low emissivity of diamond.

The earliest diamond windows were attached to flanges using an aluminum diffusion bond. Although this worked well, the aluminum was in contact with the cooling water and corrosion of the seal caused a number of gyrotron vacuum failures. The development of an $\mathrm{Au} / \mathrm{Cu}$ braze by $\mathrm{CPI}$ eliminated this problem, but in some cases window contamination occurred during brazing. This contamination changed the emissivity of the windows in the infrared and increased the microwave absorption.

It is essential that the window braze oven be kept extremely clean so that window contamination does not occur during the brazing. Contamination can be diagnosed in service using infrared imaging. A clean window will be nearly transparent at $3.5 \mu$ s, so contamination can be diagnosed from an increase in the emissivity of the window when it is transited by a high power microwave beam. In Fig. 1, the left window is clean and the right one is contaminated. The contamination will result in abnormally high apparent temperatures inferred from IR measurements. In Fig. 2 the time dependence of the apparent central temperature of three windows for long pulses is plotted. Although the clean window is the thickest of the three, its radiation temperature is the lowest. The other windows both suffer from surface contamination of different 

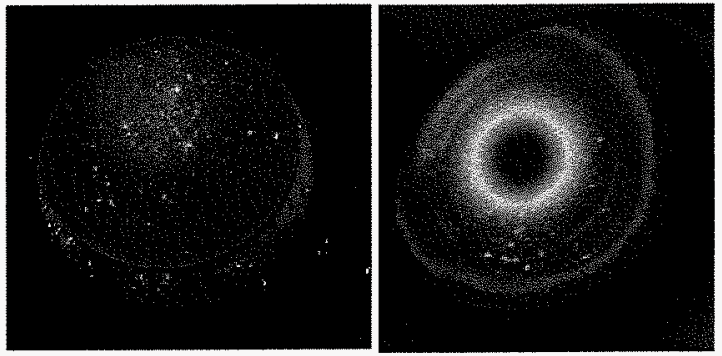

Fig. 1. Infrared images of two diamond gyrotron windows, a clean one on the left and a contaminated one on the right. The emissivity of the coating greatly exceeds that of diamond and invalidates temperature measurements made assuming clean conditions.

severity, which arose during the braze. In the worst case, the pulse length was restricted due to inability to diagnose the true temperature. Coatings on the diamond windows do increase the rf absorption and can lead to window failure. Diamond windows have been cleaned of surface contamination successfully by grit blasting with $3 \mu \mathrm{s}$ alumina, although obviously this must be accomplished on the inside surface prior to final assembly of the gyrotron. Contamination on the outside of the window can be removed with this technique even after the gyrotron has been assembled.

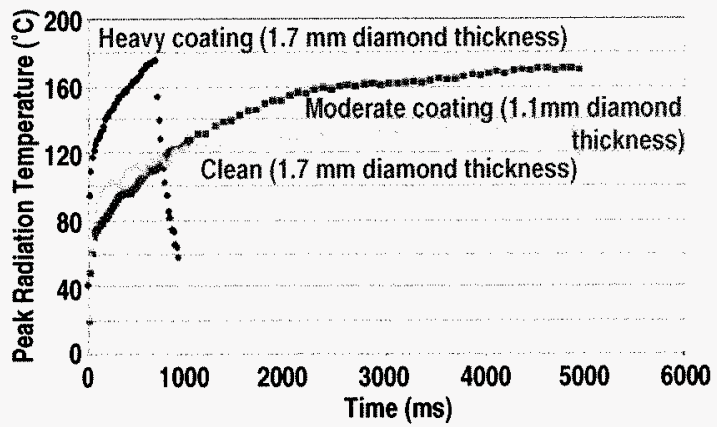

Fig. 2. Peak central temperatures of three diamond windows inferred from their infrared images. The window with the worst contamination subsequently failed in service, possibly due to a combination of factors including excessive microwave absorption due to contamination.

\section{Gyrotron Parasitic Instability}

The first gyrotron in the present group was found to be generating low frequency emission, measured at several kilowatts, at about $100 \mathrm{MHz}$ in addition to the emission at the desired frequency of $110 \mathrm{GHz}$. The emission was at the bounce frequency for electrons reflecting from the increasing magnetic field region in the cavity and caused serious problems for the controls and monitoring circuits. Although several attempts were made to damp the instability through the application of a capacitive filter across the gyrotron insulator and iron rings in the gun region, in order to operate the gyrotron, it proved to be necessary to shield and filter extensively while modifying several circuits to reduce their impedances. The spectrum of the parasite is shown in Fig. 3 , for a low current case in which it is barely excited and for a full current case with robust emission.

\section{TRANSMISSION LINES}

\section{A. Coupling to Waveguide}

The boron nitride windows installed on the Gycom gyrotrons absorb about $4 \%$ of the transmitted rf and can be heated to their operational limit of about $1000^{\circ} \mathrm{C}$ with a $2.0 \mathrm{~s}$ full power pulse. In addition, the peak permissible power density must not be exceeded. Therefore in these gyrotrons the rf beam optics were designed intentionally to spread the gaussian beam over the $10 \mathrm{~cm}$ diameter $\mathrm{BN}$ window. Once the beam exited the gyrotron, a pair of mirrors provided phase correction and focusing to couple the rf beam into the $31.75 \mathrm{~mm}$ diameter waveguide. The best efficiency which could be achieved for this process has been about $85 \%$. For the Gaussian rf beams generated by the gyrotrons with diamond output windows, the coupling efficiency has been about $93 \%$ $95 \%$.

With the two mirror phase correction system it is possible to change both the injection angle of the $\mathrm{rf}$ as it enters the waveguide or the transverse position over limited ranges or both. The high quality Gaussian rf beams from the diamond window gyrotrons do not require phase correction and can be coupled into the waveguide using a single ellipsoidal mirror, although the transverse motion and the angular change are then coupled. In this case the axis of the rf beam is placed on the mechanical axis of the coupling system using a spool piece made to accommodate any non-perpendicularity of the $\mathrm{rf}$ beam as it exits the gyrotron. Transverse shifts in the horizontal plane at the waveguide entrance can then be made by translating the coupling mirror toward or away from the gyrotron. Transverse shifts in the vertical plane cannot be made. It has been found that, although non-coaxiality of the waveguide and $\mathrm{rf}$ beam of a few tenths of a degree does not result in appreciable mode conversion, damage to the waveguide line can occur if components such as miter bends are located close to the coupling mirror. For longer initial waveguide distances the filtering provided by the waveguide eventually centers the rf beam. Nevertheless, coaxiality to better than $0.2 \%$ must be achieved, and this requires careful free space measurements of the rf beam trajectory after the coupling mirror.

\section{WAVEGUIDE LINES}

The transmission lines in the DIII-D system are made up from $2 \mathrm{~m}$ long sections of circular corrugated waveguide $31.75 \mathrm{~mm}$ in diameter. The waveguide is evacuated and there are no blocking windows separating the gyrotrons from the tokamak. Waveguide joints are sealed using metal Helicoflex seals except that joints which are expected to be subjected to disassembly, such as during component testing, are sealed using ethylene propylene seals, which do not appreciably absorb leakage microwave power. Polarization control is provided by pairs of grooved mirrors integrated into miter bends. Typical lines have about ten miter bends and are about $90 \mathrm{~m}$ in length. The measured loss in a complete line is about $20 \%$.

The waveguide pressure near the tokamak is $<1 \times 10^{-6}$ Torr and the base pressure in the coupling optics chamber near the gyrotron is about $1 \times 10^{-7}$ Torr prior to a pulse, rising to about $5 \times 10^{-5}$ Torr on a typical $1-2 \mathrm{~s}$ pulse. The pressures in the waveguide run at intermediate locations are not routinely 

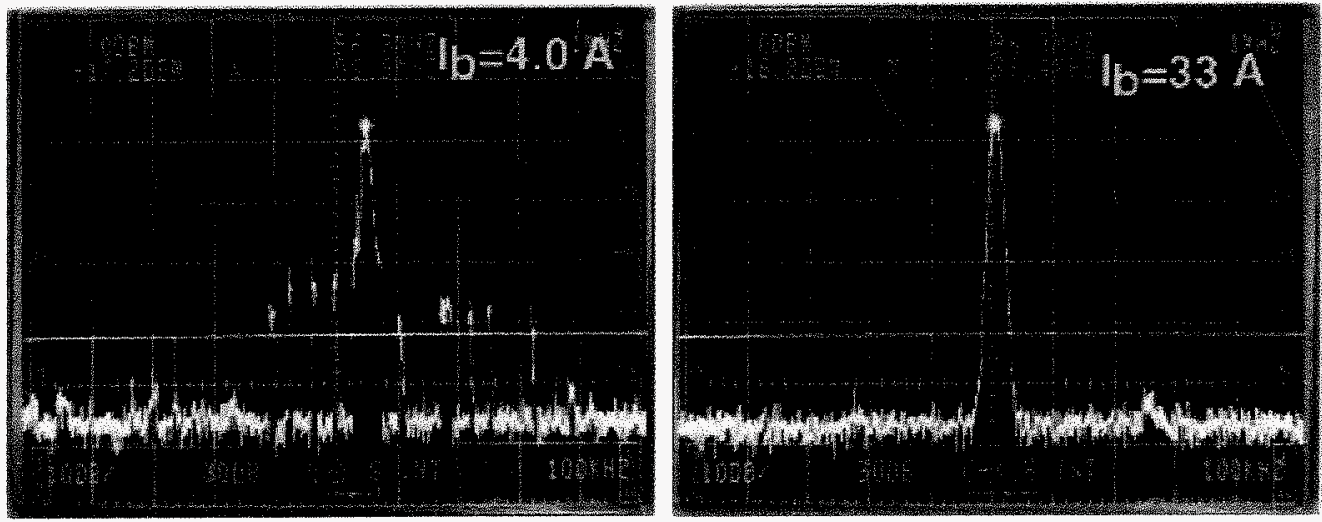

Fig. 3. Parasitic emission spectrum near $100 \mathrm{MHz}$. The instability is driven by the electron beam at approximately the bounce frequency inside the gyrotron. Emission is several kilowatts.

measured, but no evidence for waveguide arcing has been seen.

\section{LAUNCHERS}

The rf power is launched into the tokamak from mirror assemblies which have provision for scanning two beams both poloidally and toroidally. The $\mathrm{rf}$ is launched from uptapered waveguides to reflect from a weakly focusing mirror and then a flat steering mirror. At one point a failure in the shutter retraction mechanism allowed the rf to strike the edge of the carbon composite shutter. This caused an arc, which, driven by the $\mathrm{rf}$ power, cut through both sides of the aluminum waveguides. To prevent a recurrence, Langmuir probes were installed between the two uptapers and video cameras were mounted to monitor the launchers during pulses. As an additional precaution, the aluminum waveguides were replaced by stainless steel, plated on their inner bores with silver. Temperatures of the mirrors have been monitored using resistance temperature devices. Thus far, no problems have been observed with these diagnostics, suggesting that the critical factor is the avoidance of any high density local gas source at the launcher mouth. In Fig. 4, one of the launchers is shown in cutaway from the plasma side along with a video image of the launcher taken in plasma light from the laboratory side. The video and Langmuir probes provide good protection against development of arcs.

\section{DUMMY LOADS}

Initially inconel dummy loads were installed on all the systems. These loads, water cooled cylinders with off-axis injection of the rf beams, had slow thermal response and were somewhat reflective, resulting in heating of the input waveguides and some concern about gyrotron operational stability. Development of a mode conversion load, which could be inserted in series with the inconel loads, reduced the time response and greatly reduced the reflected power. The mode conversion loads [4] are water jacketed waveguide having an axial profile of the groove depths which causes conversion of the $\mathrm{HE}_{1,1}$ input mode to highly damped $\mathrm{EH}_{1,1}$ surface modes. The mode conversion loads absorb about $60 \%$ of the incident power and are extremely effective at damping rf power reflected back from the inconel loads.

\section{POWER SUPPLIES}

Each of the DIII-D $1.0 \mathrm{MW}$ class gyrotrons requires approximately $40 \mathrm{~A}$ at $80 \mathrm{kV}$, with the possibility of modulation at square wave frequencies up to about $10 \mathrm{kHz}$. These requirements have been met using d.c. high voltage from a transformer/rectifier providing up to $110 \mathrm{kV}$ at $100 \mathrm{~A}$ followed by series tetrode rectifier. Two configurations are in use. In the first, two gyrotrons in parallel, each of which requires $80 \mathrm{kV}, 40 \mathrm{~A}$ for full power $1.0 \mathrm{MW}$ output, are

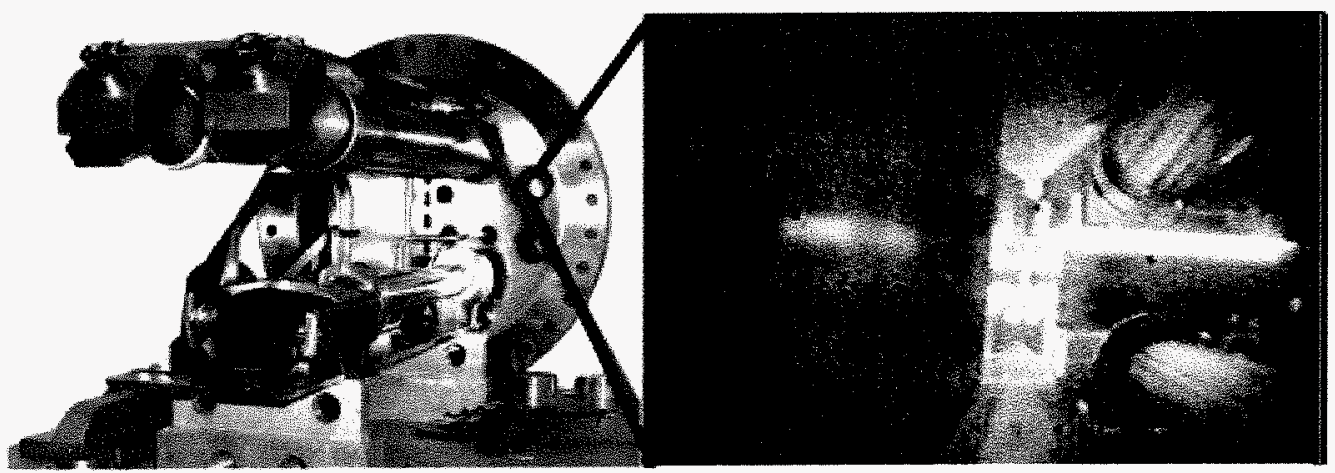

Fig. 4. Two views of a dual launcher. On the left is a cutaway photo showing the principal parts. On the right is a video frame view of the launcher, used as a protective diagnostic, from outside the tokamak. 
powered from a single regulator tube and in the second, two parallel regulators provide voltage controlled high voltage for three tetrodes, each of which is driving a single gyrotron at about the $70 \mathrm{kV}, 32 \mathrm{~A}$ level. The series parallel combination in the second case is an historical artifact to some extent, which could be replaced by single series regulators with some changes in the control system.

Initial concern about the stability of the high voltage regulation for the parallel gyrotron configuration proved to be well founded, as the regulation has been unstable when the parallel gyrotrons were operated at their maximum parameters. Circuit modeling suggested that the common flux included in the loop formed by the high voltage cables connecting the tetrode and the gyrotrons could result in a circuit instability, but it has not been possible thus far to damp the instability except by operating the gyrotrons about $1 \mathrm{~A}$ below their maximum currents.

The gyrotrons are protected against damage during sparkdown by a crowbar circuit with microsecond response. In the event of a gyrotron arc, the crowbar is required to limit the maximum energy delivered to the arc to less than $10 \mathrm{~J}$. In fine wire short circuit tests it was found that the crowbars, consisting of four series stages of ignitrons gated by IGBT or SCR triggers, could limit the energy to about $4 \mathrm{~J}$. The first design of the crowbar stacks used thyratrons, however these devices suffered from metal deposition on the insulator surfaces and were unusable after only a few crowbar shots.

\section{CONCLUSION}

The gyrotron installation on the DIII-D tokamak is a complex system of microwave generators, high voltage regulators, vacuum pumping, transmission lines, antennas, cryogenic magnets, controls and protective circuits. Continuing development based on experience has taken advantage of state of the art components and techniques resulting in a unique and reliable tool for advanced fusion research.

\section{ACKNOWLEDGMENT}

Work supported by the U.S. Department of Energy under Contract number DE-AC03-99ER54463.

\section{REFERENCES}

[1] Communications and Power Industries, Palo Alto, CA, USA.

[2] Gycom, Nizhny Novgorod, RUSSIA.

[3] J. Lohr, R.W. Callis, e.t al., Proc. 14th Topical Conf, Radio Frequency in Plasmas, T.K. Mau and J. DeGrassie, eds, American Institute of Physics, Melville, NY, p314 (2001).

[4] John L. Doane, Int. J. Infrared and Millimeter Waves, 14, 363 (1993). 